\title{
Abrupt climate changes recorded in loess sequences
}

Denis-Didier Rousseau ${ }^{1,2}$ and Adriana Sima ${ }^{1}$

\begin{abstract}
The glacial-interglacial and orbital-timescale oscillations imprinted in loess records have been studied for a long time. Researchers have recently started to investigate millennial and sub-millennial variations by means of high-resolution field studies and data analyses combined with modeling experiments.
\end{abstract}

The terrestrial sediments known as "loess" represent an important archive of paleoclimatic variability. Mineral material mobilized by wind at the ground surface was transported over distances from a few hundred to thousands of kilometers and deposited back on the ground where it underwent a gradual transformation into loess sediment. The largest loess deposits are found in the Northern Hemisphere, primarily because the continental surface is much larger than in the Southern Hemisphere. Depending on their location on the globe (Fig. 1), the deposits have formed under the influence of different climate factors, and contain more or less detailed records of regional climate change. Here we review the current knowledge about the three main loess regions of the Northern Hemisphere. The many underlying references are provided in an extensive online archive of references, listed by regions.

\section{European loess}

An almost continuous loess band stretches, along approximately $50^{\circ} \mathrm{N}$, from western Europe to the Dnieper valley in Ukraine. In this band, loess sequences mainly record the North-Atlantic millennial-scale climate changes of the last glaciation (between ca. 110-15 ka BP): the Dansgaard-Oeschger (DO) events and Heinrich stadials (Rousseau et al. 2007, 2011). The DO events correspond in the Northern Hemisphere to abrupt warmings, of about $10^{\circ} \mathrm{C}$ in Greenland within $50-100$ years, and are followed by a more gradual return to cold (stadial) conditions. The Heinrich stadials represent particularly cold climate episodes caused by massive iceberg discharges from the Northern Hemisphere ice sheets known as Heinrich events.

Multidisciplinary loess studies and detailed chronological analyses indicate a strong correlation between these climate variations and European loess sedimentation. In the $50^{\circ} \mathrm{N}$ European loess band, the alternating warm and cold episodes are clearly imprinted in the stratigraphy as a succession of doublets of paleosol-loess units, in particular during marine isotope stages 3 and 2 (between approx. 60-15 ka BP). The soils were formed during the relatively warm North-Atlantic phases (Greenland interstadials) associated with DO events, when the eolian sedimentation was reduced or even absent. The degree

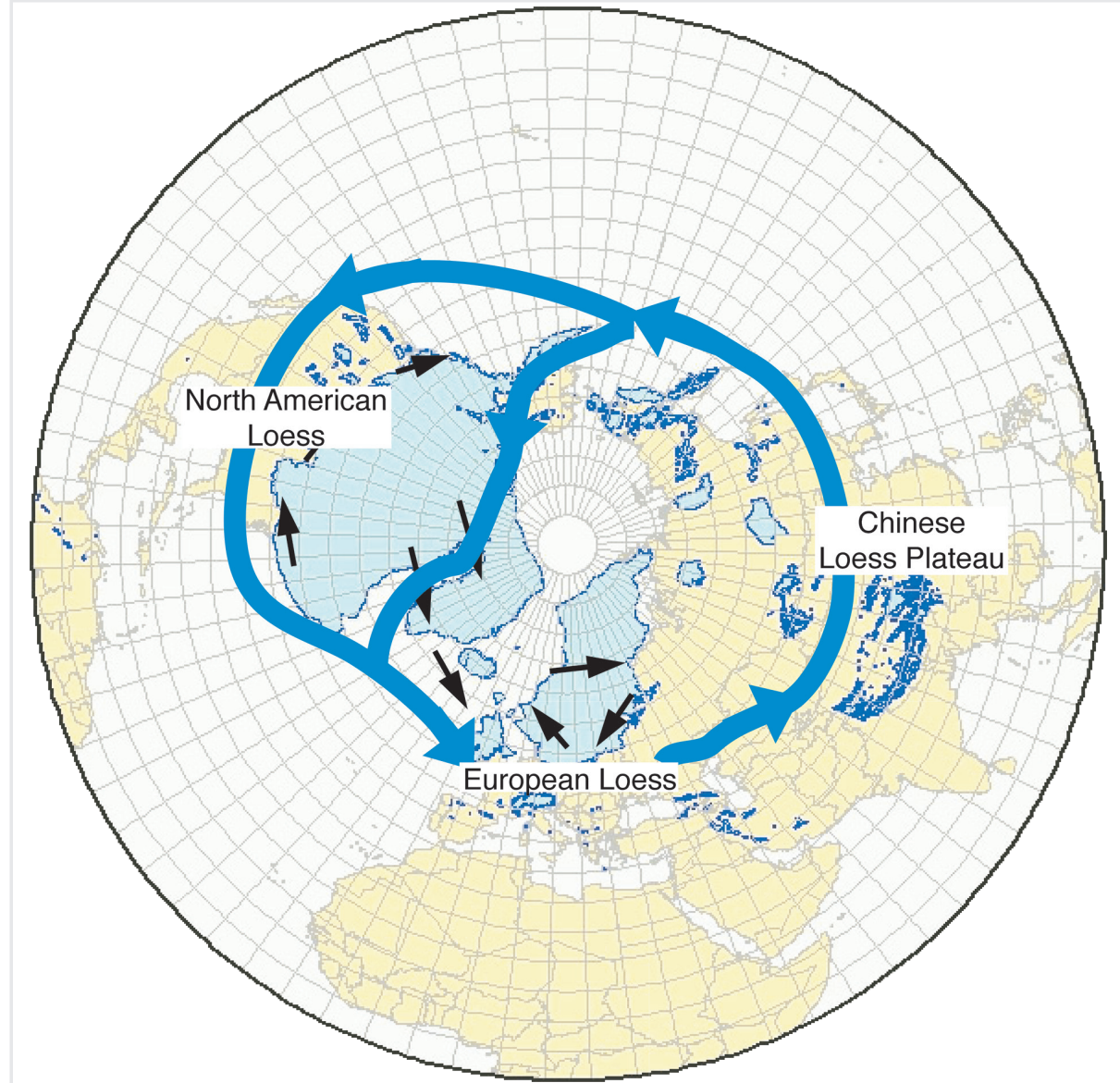

Figure 1: The Northern Hemisphere ice-sheets (in light blue) and glaciers (dark blue dots) at the Last Glacial Maximum (map compiled by Jürgen Ehlers, available at www.qpg.geog.cam.ac.uk/lgmextent.html), the schematic location of the polar jet stream (blue arrows), wind patterns (black arrows) generated by the presence of the ice sheets (Kutzbach 1987), and (labeled) the loess regions discussed in the text.

of development of each soil depended on the duration of the corresponding warm episode. The loess units correspond to the cold North-Atlantic phases (Greenland stadials and Heinrich stadials), when the dust cycle was very active and the sedimentation rates were high. Other loess deposits can be found in Europe at lower latitudes, but the millennial climate variations represented by the alternation of paleosols and loess units are absent in the stratigraphy, suggesting drier conditions than in the $50^{\circ} \mathrm{N}$ loess band.

Recent studies have employed numerical modeling to investigate the mechanistic link between the North-Atlantic millennial climate signal and the loess sedimentation variations in Europe around $50^{\circ} \mathrm{N}$ (Sima et al. 2009, 2013). These studies focused on variations in dust mobilization, reasonably assuming that the deposition fluxes strongly depended on the emission fluxes. An important aspect of modeling the formation of loess deposits in Europe is to identify the geographical areas that were potentially subject to deflation during glacial times, but are not anymore under present-day climate conditions.

For Western Europe, data-based studies have shown that the continental shelf that emerged during glacials (when sea-level dropped), especially in the English Channel and the 
North Sea, used to be a strong dust deflation area. Transported from there by westerly winds, fine material must have reached loess deposits located many hundreds of kilometers away, together with coarser material from nearer sources, such as large river valleys or periglacial outwash plains. Modeling results (Sima et al. 2009) point to vegetation changes in response to the millennial climate variations as a key factor in modulating dust emission, and hence ultimately also in controlling loess sedimentation (Fig. 2). They also show the strong seasonality of the dust cycle. Dust emission was mainly active in spring time when the snow cover had melted, the topsoil layer had begun to thaw, the surface winds were still strong (even though weaker than in winter), and the vegetation had not yet developed enough to completely protect the surface from wind erosion. The colder the climate, the later the emission season started, and the later it ended. Numerical experiments generated about one month of delay for a given region between the warmest ("Greenland interstadial") and the coldest ("H stadial") simulated climate state.

For Eastern Europe, previous data-based studies only suggested the general direction in which the source areas should have been located with respect to the investigated loess deposits. Numerical modeling results (Sima et al. 2013) now show the likely dust source areas (Fig. 2). They also suggest that Heinrich stadials, even though generally colder and drier than the other stadials, were not necessarily dustier. Dust storms appeared to be generally less frequent during Heinrich stadials, but individual events could become stronger than during non-Heinrich stadials. These modeling results are in agreement with findings of relatively coarser-grained layers in loess sequences interpreted as HeinrichStadial signature.

\section{Asian loess}

In the eastern part of Eurasia, the sedimentation in the Chinese Loess Plateau (Fig. 1), which commenced about 22 Ma ago, strongly depended on fluctuations of the Southeast Asian monsoon. Initial investigations on loess sequences from this area have identified orbital timescale variations related to changes in the three astronomical parameters: eccentricity, obliquity, and precession. Some series from the north of the Chinese Loess Plateau also exhibit particle-size variations with millennial frequency, similar to the DO oscillations observed in North Atlantic records. A correlation, mainly based on luminescence dates, has been established between intervals of coarse loess layers and Greenland stadials (without particularly distinguishing the Heinrich stadials), while intervals of finegrained loess were associated with the DO warming events. The grain size changes are interpreted as reflecting variations in the strength of the atmospheric circulation during the SE Asian winter monsoon over the deserts of Mongolia and northern China, the main dust suppliers to the Chinese Loess Plateau.

The Chinese loess sequences do not contain any paleosols related to DO events, because the corresponding climate is too dry to allow pedogenesis. Alternating paleosol-loess units similar to those observed in Europe along $50^{\circ} \mathrm{N}$ can, however, be found in Siberian loess deposits north of Lake Baikal. The available radiocarbon dates allow the Siberian paleosols to be correlated with the DO events and suggest that the impact of the North-Atlantic millennial climate variations reached at least as far east as Lake Baikal.

\section{North American loess}

The North American loess deposits have recorded various influences, mostly related to climate changes originating in the North Atlantic and Pacific regions. According to climate simulations run with an Earth
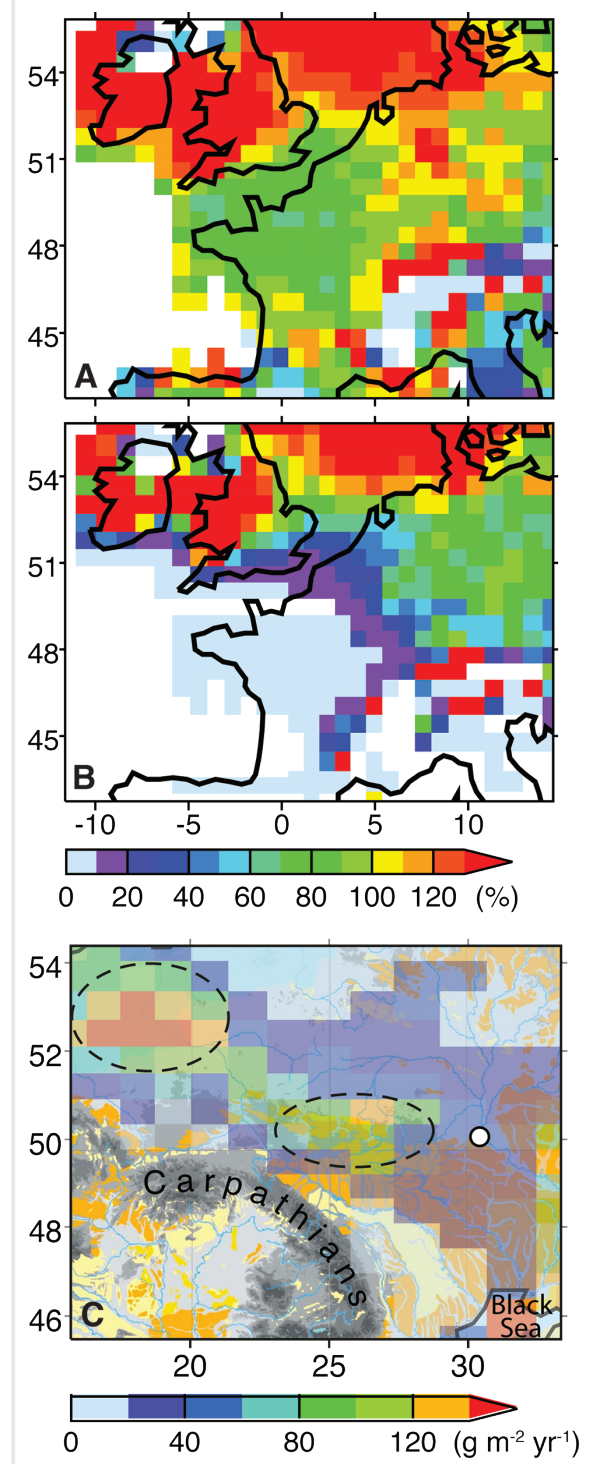

Figure 2: (A) Simulated dust emission fluxes for Western Europe for a "Greenland interstadial" (GIS) are relatively close to those for a "Greenland stadial" (GS) when the GIS and GS fluxes are computed without taking the vegetation effect into account (GIS/GS flux ratio between $70-130 \%$ ); (B) the flux ratio GIS/GS strongly decreases when the vegetation effect of inhibiting eolian erosion is taken into account (modified from Sima et al. 2009). (C) Simulated dust emission fluxes for Eastern Europe for a GIS, superimposed on a topographic map; the most active spots (indicated with dotted lines) have probably been important sources for some Eastern European loess deposits (in yellow, in background), such as those around Stayky (white dot) in NW Ukraine (modified from Sima et al. 2013). system model of intermediate complexity, the eastern part of North America should have been affected by the DO and Heinrich abrupt climate changes, but very few loess deposits can be found there to verify this model result. On the other hand, modeling results indicate that much of the Great Plains, where the thickest North American loess deposits are located, and the western part of the continent were not influenced by DO and Heinrich events. Indeed, the succession of paleosol-loess units in sediments in the state of Illinois, $120 \mathrm{~km}$ south of the Laurentide ice sheet margin at its maximum extent, is interpreted (using radiocarbon dates) as reflecting sub-millennial timescale inflow of air from the Gulf of Mexico, with a periodicity of about $450 \pm 100 \mathrm{yr}$. Loess sequences located further west, mainly in the state of Nebraska, show bedded mineral layers corresponding to even finer timescales. These were formed as a result of the transport of material during the Last Glacial Termination ( 23-12 ka BP) from nearby areas, including the outwash areas of the southwest margin of the Laurentide ice sheet and the east margin of the Cordilleran ice sheet.

\section{Outlook}

Many loess deposits, especially across the Northern Hemisphere, have recorded past climate changes at millennial and sub-millennial timescales. Some loess sequences also contain evidence of particularly strong dust events with a much shorter characteristic timescale. Thus, during Marine Isotopic Stage 5, European sequences (especially from Central Europe) have recorded dust storms of continental magnitude in response to atmospheric blocking episodes (Rousseau et al. 2013). More effort is needed, on the data side, to better quantify the past dust-cycle variations at these different timescales, and on the modeling side, to more realistically simulate them.

\section{ACKNOWLEDGEMENTS}

The authors were supported by the ANR ACTES project (ANR-08-BLAN-0227). DDR was supported by the Alliance program for a Visiting Professorship at Columbia University. This is LDEO contribution 2014-7803.

\section{AFFILIATIONS}

'Laboratoire de Météorologie Dynamique \& CERES-ERTI, CNRS - Ecole Normale Supérieure, Paris, France 'Lamont-Doherty Earth Observatory of Columbia University, Palisades, USA

\section{CONTACT}

Denis-Didier Rousseau: denis.rousseau@Imd.ens.fr

\section{REFERENCES}

Full reference list under:

www.pages-igbp.org/products/magazine/ref2014_2.pdf Rousseau DD et al. (2007) Geophys Res Lett 34, doi:10.1029/2007gl031716

Rousseau DD et al. (2011) Clim Past 7: 221-234

Rousseau DD et al. (2013) Clim Past 9: 2213-2230

Sima A et al. (2009) Quat Sci Rev 28: 2851-2866

Sima A et al. (2013) Clim Past 9: 1385-1402 